\title{
A Model of Science to Base the Introduction of Aspects of Nature of Science in Teaching Contexts and to Analyse such Contexts
}

\author{
Monique Santos \\ Brazil \\ Poliana Maia \\ Brazil \\ Rosária Justi \\ Brazil
}

Some Science Education researchers have emphasised the importance of discussing aspects of Nature of Science, in a contextualised, and/or explicit, and/or integrated manner within science teaching. Distinct alternative approaches, known as contemporary and comprehensive ones, identify what to introduce in science teaching; however, none of them didactically characterise the meaning of such aspects of Nature of Science. Seeking to contribute to filling this gap, in this paper we have adopted one of these approaches as the theoretical background and have expanded it. For this, we have studied each of the disciplinary perspectives that are part in such an approach. Thus, we characterise such disciplinary perspectives, meaning that we identify and detail the meaning of the aspects of Nature of Science related to each of them, as well as their scopes and limitations. This also results in changes to its visual representation, an analogue-based one. As a result, the new approach can be used both by teachers, in planning more authentic teaching situations, and by researchers in analysing data collected in teaching contexts. Both functions are exemplified in this paper, being taken from some studies that have been, or are being, conducted. By discussing both functions, we identify consequences for science teaching in basic education, for teacher education and for research in the area.

Keywords: Nature of Science; Science Teaching; Theoretical Tool; Methodological Tool.

\section{Introduction}

Over the last few years, some research papers have been published in the area of Science Education ${ }^{1}$ stressing the importance of Science Education being more authentic (e.g., Archer et al., 2010; Millar \& Osborne, 1998; Osborne et al., 2003), which means it involves teaching situations that are closer to Science itself (Gilbert, 2004). This position is in line with the goal of promoting a wider scientific literacy, that contributes to the qualification of people with good critical and reflective skills (Sasseron \& Carvalho, 2011), who can understand scientific knowledge and think about it (Roberts, 2011). Such research studies have highlighted the importance of a teaching style that can

1 We stress that we have decided to use the term Science with an initial capital S as this refers to the school subject or the area of knowledge. 
contribute to the development of a wider view about Science $^{2}$, to the extent that it favours understanding and thought about the processes of construction of scientific knowledge, including production, communication, evaluation, review, and validation.

From this viewpoint, many researchers specialised in the area have carried out investigations on the importance of introducing aspects of Nature of Science (NOS) into Science teaching (e.g., Abd-El-Khalick, 2012; Allchin, 2011, 2012a, 2013, 2017; Irzik \& Nola, 2011, 2014; Justi \& Erduran, 2015; N. G. Lederman et al., 2002; Matthews, 2012). In the specialised literature of this area, we can find many definitions for the term NOS. These include the definition presented by McComas (2008) which reflects the general perspective taken up in this article. According to McComas, NOS can be defined as:

[...] a hybrid domain which blends aspects of various social studies of science including history, sociology and philosophy of science combined with research from the cognitive sciences such as psychology into a rich description of science; how it works, how scientists operate as a social group and how society itself both directs and reacts to scientific endeavours (McComas, 2008, p. 249-250).

Such researchers have also stressed the need for NOS to be discussed in a manner that is contextualised, and/or explicit, and/or integrated (with some of them stressing one or two manners more than another one. The contextualised approach refers to the presence of a context as a foundation, like the historical context when teaching different models for the atom; the explicit approach refers to open discussion of aspects of NOS that have (or have had) an influence on the construction of scientific knowledge (e.g., the motivation of Marie Curie for explaining unexpected data that resulted in the discovery of the chemical element Radium); and finally the integrated approach refers to the incorporation of aspects of NOS to the development of one or more scientific contents within the curriculum (e.g., the multiplicity of, and relationship between, models for the atom). We must mention that, in specialised literature, it is more common to find authors that mention, and/or have work based on, the contextualised and explicit manner to introduce aspects of NOS in teaching. However, work based on the three approaches in a balanced way, never stressing one or two of them, in preference to the other, is not common. In addition, with regard to the contextualised approach, it is important to mention that it only becomes significant if the context included as a foundation is relevant to the context in which the students are inserted. With regard to the integrated approach, we understand that it goes a bit beyond just incorporating aspects of NOS in the development of one or more items of curricular scientific content in isolation; in other words, the aspects of NOS should be incorporated into the general goals of the teaching-learning process. In this way, an approach that is contextualised, explicit, and integrated to aspects of NOS in the teaching of and about Science, in a balanced way, can favour not only the learning of curricular scientific content, but also the development of a much more encompassing view about Science, to the extent that it adds power to the construction of knowledge of and about Science in its construction contexts, with their

2 In this paper, the phrase about Science is used as synonymous with Nature of Science. 
own limits and scopes, thereby bringing the students closer to these contexts.

In this regard, Driver et al. (1996) not only recognise the importance of including aspects of NOS in the curriculum, as also show five benefits the learning of such aspects can bring: (i) understanding of the Science processes; (ii) informed decision making ${ }^{3}$ about socioscientific issues; (iii) appreciation of Science as an essential element within modern-day culture; (iv) awareness of the standards of the scientific community; and (v) learning of curricular scientific content in greater depth. Nevertheless, over two decades later, on analysing the curriculum in nine countries, Olson (2018) showed that very rarely (with the sole exception of the Australian curriculum) are aspects of NOS given as goals of the learning process.

Therefore, despite the consensus among researchers specialised in this area with regard to the importance and the benefits of including aspects of NOS in the curriculum (Martins, 2015), Olson (2018) states that this dimension has not been taken on by the curricula around the world as goals of the teaching-learning process. This makes it relevant to consider that there is a problem with one of the dimensions in relation to the introduction of aspects of NOS, either in the dimension regarding what to introduce (that is, which aspects of NOS - focus of this paper) or how to introduce (Allchin et al., 2014; Irzik \& Nola, 2011; Matthews, 1998).

With regard to the issue of what to include in the curriculum, some researchers (e.g., Abd-El-Khalick et al., 1998; N. G. Lederman, 2006; N. G. Lederman et al., 2002) believe that it is possible, and necessary, to make a list of certain aspects of NOS that they consider relevant. From this perspective, Norman Lederman and his collaborators drew up a list of seven tenets that should be taught to students: scientific knowledge is tentative, empirically based, subjective (theory-laden), partly the product of human inference, imagination, and creativity, socially and culturally embedded; observations are different from inferences; and scientific theories and laws are different from each other and have distinct functions (N. G. Lederman, 2006).

As highlighted by Deng, Chen, Tsai, and Chai (2011), based on this proposal and also on a wide consensus between researchers specialised in the area and international curriculum documents, several empirical studies have been carried out with the main aim of characterising the views of teachers and students about Science, as also to propose and validate instruments ${ }^{4}$ for carrying out such characterisations. The publication of these studies led to widespread publicity of this proposal, as shown by the high number of publications that use the list of tenets as a theoretical background (e.g., Bayir et al., 2014; Cakici \& Bayir, 2012; J. S. Lederman \& Khishfe, 2002; J. S. Lederman \& Ko, 2002; N. G. Lederman et al., 2002; Schwartz et al., 2008). In the last two or three decades, such a proposal became known as consensual view of NOS (Martins, 2015), being

3 As we see it, it shall not always be possible, or necessary, for the student to reach a decision. In Justi et al. (2019) we present an in-depth discussion on this issue.

4 These instruments are often questionnaires involving the use of a Likert scale, which is often criticised by specialised literature for not favouring a clear and/or reliable explicitation of the ideas as presented by the respondents. 
predominant in the literature of the area (Erduran et al. 2019). However, in the last few years, some researchers (e.g., Allchin, 2011, 2013, 2017; Erduran \& Dagher, 2014; Irzik \& Nola, 2011, 2014; Justi \& Erduran, 2015; Martins, 2015; Matthews, 2012; McComas, 2008; Nielsen, 2013; Osborne et al., 2003; van Dijk, 2011; Weinstein, 2008; Wong \& Hodson, 2010) have criticised this proposal. For these authors, the tenets shown in the list are beset with many underlying problems. The most significant problems are: (i) they are presented in a declarative manner; (ii) they could favour the view that Science is only restricted to them; and (iii) they may not favour understanding by teachers, as they present some ideas arising from Philosophy in a complex and abstract manner.

One of the main critics of the list of tenets as proposed by Lederman and his collaborators is Allchin $(2011,2013,2017)$. His view is that the presentation of a list of tenets in a declarative manner does not contribute to scientific literacy because understanding, recording and/or memorisation of the list do not help students to exercise critical thinking, for example, about the influences that the process of construction of scientific knowledge may wield on conscientious individual and/or social decisionmaking. In other words, the list of tenets does not contribute to a functional understanding of Science (Allchin, 2014).

In this regard, thinking about the context of Science teaching, Allchin (2011, $2013,2017)$ proposed an alternative approach to the list of tenets based on the idea of Whole Science that led to the proposal of the Profile of Dimensions of Reliability in Science (PDRS). According to the author, the term Whole Science can be understood as a holistic way of regarding Science. Thus, according to Allchin (2012b), instead of presenting a list of tenets to the students, it would be more appropriate to present, in a contextualised, explicit, and integrated manner, a profile of dimensions that is constituted by epistemic functional categories related to: (i) observations; (ii) research methods; (iii) instruments; (iv) patterns of reasoning; (v) historical dimensions; (vi) human dimensions; (vii) collaboration and competition among scientists; (viii) socio-cultural dimensions; (ix) economics/funding; and (x) communication. Briefly, what Allchin defends is that the analysis of the procedures involved in scientific practice and the validation of the knowledge produced based on these could be conducted based on functional epistemic categories that make up this profile.

Based on the viewpoint of Whole Science, Allchin (2013) brings a collection of historical and contemporary cases, with the identification of the functional epistemic categories that could arise from these. This shows itself to be coherent, as the author defends the perspective of Science under construction (Latour, 1987). In this book, he also presents some proposals based on which students could work in groups, structuring ideas to take a position either in favour of, or against, a certain standpoint and/or scientific statement. However, so far (up to the start of 2020), very few are the studies in specialised literature that address the use of cases based on the perspective of Whole Science (e.g., Carvalho \& Justi, 2019; Justi \& Santos, 2019; Santos, 2018) within the context of Science teaching. 
In a nutshell, apart from considering a contemporary and wide-scope view of teaching, the proposal made by Allchin $(2011,2013,2017)$ also presents a concrete proposal for the introduction of aspects of NOS into teaching, based on a collection of historical and contemporary cases. However, this proposal shows itself to be limited due to the lack of characterisation of the dimensions and functional epistemic categories related thereto that make up the PDRS. In addition, Allchin $(2011,2013,2017)$ presents these dimensions and categories grouped in different ways, in the references here mentioned, and, for these reasons, Justi and Santos (2019), and Santos (2018) made an adaptation to the PDRS to make it a functional tool and to use it in their studies.

Other critics to the list of tenets as proposed by Lederman and collaborators are Irzik and Nola $(2011,2014)$. They make a more intense criticism of the list, stating that the list makes a homogeneous characterisation of Science, meaning that this view does not consider the presence of different scientific subjects and the specificity of each one. In the light of this fact, the authors propose a new approach that they have called the Family Resemblance Approach (FRA). Irzik and Nola (2011) take Wittgenstein's idea that "the members of a family can each resemble one another in some respects but not in others" (p. 594) and, by analogy, propose that each of the scientific subjects would have some similar characteristics, and some different, when compared to others. Based on this statement, they say that we should not define Science by identifying its universal characteristics, but rather by identifying the similar and the different characteristics of each of its areas. According to FRA, this can be done by considering some categories that are connected to Science: (i) activities; (ii) aims and values; (iii) methodologies and methodological rules; and (iv) products. Some years later, Irzik and Nola (2014) widened the scope of the proposal, with the inclusion of four more categories: (v) professional activities; (vi) scientific ethos; (vii) system of knowledge certification and dissemination; and (viii) social values. Therefore, according to this proposal, Science can be defined as a cognitive-epistemic system, considering the first four categories, and as a socialinstitutional system, based on the last four. However, they stress that the two dimensions, and consequently all eight categories, which are not mutually exclusive or distinct, constantly interact with each other, and in different ways.

Even though Irzik and Nola $(2011,2014)$ have shown their desire for FRA to be used in Science teaching and even supplied some general suggestions in this direction, they do accept that this approach is theoretical. An explanation in greater detail about how it could be possible to use such ideas (which came from Philosophy) in Science teaching was proposed by Erduran and Dagher (2014). With this in mind, the authors widened the proposal made by Irzik and Nola $(2011,2014)$ with the inclusion of political, financial and organisational aspects in the social-institutional dimension, which resulted in another three categories: (ix) financial systems; (x) political power structures; and (xi) social organisations and interactions ${ }^{5}$. They also proposed a set of visual representations, known as Generative Images of Science, with the ultimate goal of facilitating the

5 In international specialised literature, this expansion is known as Expanded FRA, Extended FRA, and Reconceptualised FRA to NOS (RFN). We also point out that, in the expanded version, categories (i) and (iv) are known as practices and knowledge, respectively. 
communication of philosophical ideas considered abstract and complex and, as a result, the understanding thereof by teachers. As from this moment, the approach, formerly considered merely technical, started to be methodological and thus possibly applicable to the context of Science teaching (as in Erduran et al. 2019; Kaya \& Erduran, 2016; Kaya et al., 2019). On the other hand, the main representation of the expanded version of FRA - which the authors know as the "FRA wheel" (Erduran \& Dagher, 2014, p. 28) - consists of a centre circle divided into quadrants and surrounded by two other circles, similarly subdivided. According to the authors:

[...] the boundaries between the two circles (or spaces) and their individual compartments are pervious, allowing fluid movement across. In reality, these components are not compartmentalised but flow naturally in all directions (Erduran \& Dagher, 2014, p. 28-29).

However, contrary to the aspects here described, the representation itself shows divisions, and does not contain any graphic elements that would suggest movement. Because of these discrepancies, we feel that it cannot be easily understood by teachers.

In addition, out of the researchers who criticised the consensual view of NOS, Allchin (2012b, 2013) was the researcher to have made clear and concrete proposals about how to introduce aspects of NOS in Science teaching from a contextualised, explicit, and integrated manner (from historical and contemporary cases).

However, considering what to introduce, which means, in other words, which aspects of NOS are to be introduced, neither the alternative approach based on the concept of Whole Science which led to the PDRS, nor the approach based on the idea of Family Resemblance (even after the expansion made by other authors) do didactically characterise the meaning of the aspects of NOS (known as functional epistemic dimensions and categories, in the first approach, and as dimensions and categories related to Science, in the second). Another point we are concerned with is the confirmation that inappropriate views about Science are not limited to students, also being identified among teachers active in the area (Guerra-Ramos, 2012). This makes it necessary to have a construct that contributes so that teachers, who are not specialists in NOS, (i) understand how ample these dimensions and categories, used in the characterisation of construction of scientific knowledge actually are and, at the same time, (ii) are guided to think based on these dimensions and categories and also consider the multiple ways in which these can be present, as a result of the plurality of Science (which means acknowledging the existence of different methods and processes for production, communication, evaluation, review and validation of scientific content).

In this context, we highlight the importance of the existence of other theoretical and methodological proposals that didactically characterise the meaning of each aspect of NOS, so that teachers at different levels of teaching may have access to, and duly understand, what parts of NOS to introduce in Science teaching. This is because, according to Kaya et al. (2019), "teachers' own views and understanding of NOS can influence how they teach NOS” (p. 4-5). Therefore, when we prepare or expand an alternative 
approach to the introduction of NOS in teaching, it is important that we be concerned with the understanding that teachers (in-service or preservice ones) could have (or not have) of this approach, so that the introduction of aspects of NOS does in fact occur, in an appropriate and effective way. Thus, just like Moura et al. (2020), we believe that such aspects of NOS should be appropriated in a critical way by teachers, meaning that, based on the understanding of an alternative approach for the introduction of NOS into teaching, teachers may think over the importance of introducing such aspects and how to introduce them, depending on the level of teaching and also the context in which the students find themselves.

Due to this, this article, which is theoretical in nature, has the main goals of presenting and discussing the expansion of an alternative approach, both that of lists of tenets as also those based on the ideas of Whole Science and Family Resemblance. In addition, this approach can also be called a model (and has been named as such) because, as mentioned by Gilbert and Justi (2016), models are epistemic artefacts, that is, reasoning tools. Such an approach (i) identifies and details the meaning of aspects of NOS that could be introduced into teaching so as to favour a wide understanding of the significance of Science, thus contributing for the filling (albeit partial) of the gap related to the question of what to introduce of NOS in Science teaching; and (ii) can be used both by teachers, on teaching NOS, and researchers, in the analysis of teaching situations in which aspects of NOS were considered, thereby expanding the contribution that already exists in specialised literature, with regard to how $w^{6}$ to introduce aspects of NOS in Science teaching. For this purpose, in the following section we present yet another approach which is an alternative to the list of tenets which, despite not being as well known as the others, contemplates a contemporary and wide-scope view of teaching, as also the other two approaches as previously mentioned. However, we base ourselves on this latter approach to reach our goal because, according to the arguments that shall be presented in the following section, we acknowledge the potential of this model for use by Science teachers.

\section{Model of Science for Science Education}

Considering the criticism which has been made with regard to the lists of tenets (as that proposed by Lederman and collaborators); the observation that the proposal raised by Allchin $(2011,2012 b, 2013)$ could favour the introduction of aspects of NOS to Science teaching; and the importance of using a representation easily understood by teachers, favouring the understanding of the proposal, Justi and Erduran $(2015)^{7}$ put forward the Model of Science for Science Education (MoSSE). The main motivation

6 In this article, we use the term how in the wider sense, meaning that the term how does not refer to operational aspects (e.g., stages to be followed for the preparation and/or conduction of activities), but rather to the general principles for guiding the introduction of NOS into teaching (e.g., areas of knowledge and aspects of NOS related to these, to be addressed in such activities).

7 Although this model was original publicised in 2015, it was created in 2012, concurrently with the proposal by Erduran and Dagher (2014). 
shown by these authors was the need to provide grounds for wide-scope discussions about Science, with Science teachers, and explicitly aimed at the Science teaching context. This model is based on two main assumptions: (i) Science is a complex cognitive, epistemic and social activity, which can and has been characterised based on a series of subject perspectives; and (ii) any arguments about Science should be based on evidence arising from distinct subject perspectives, so that Science Education may favour the development of a wider view about Science (Justi \& Erduran, 2015).

The different subject perspectives as shown in the MoSSE are:

- Anthropology of Science, which considers scientific work to be a kind of social action, while the development of scientific knowledge is a kind of cultural production;

- Psychology of Science, which studies scientists' behaviour and mental processes, as also aspects of neuroscience;

- Sociology of Science, which studies both the central role of the scientific community in society and the impact that society has on Science;

- Economics of Science, which studies the influence of economic factors on the behaviour of scientists, the distribution of financial resources intended for use in Science, and the financial operations carried out by scientific institutions;

- Philosophy of Science, whose main focuses of interest are the very meaning of Science and its epistemological aspects, in other words those related to the production of scientific content, its origins and validation;

- History of Science, that studies the development of Science and scientific knowledge over time, thus showing that scientific knowledge is provisional; and

- Cognition of Science, which studies the processes for acquisition of knowledge; in other words, how individual people think when they produce and/or understand scientific knowledge and the types of reasoning that they can use in this process.

Seeking to favour the viewing of what would be considering Science based on these disciplinary perspectives, the authors have proposed an analogue visual representation, which they have called the Science Eye (Figure 1).

This representation has been coined in analogy to the London Eye, that is one of the tallest and largest observation ferris wheels in the world (standing 135 metres tall), situated in London. The analogy with the London Eye was established initially considering that: (i) just like the view of London, the view of Science is wide in scope and extremely complex; and (ii) as each transparent glass capsule represents a subject-based perspective, each one of these can provide a different orientation for a view of Science. In addition, Science can be viewed based on one capsule (the perspective of someone who is inside one of them) or by several at the same time (from the viewpoint of an external observer). This view can also be different depending on: (i) the position that the individual person occupies within the capsule (that is, if the person adopts different 
references to discuss each subject perspective); (ii) whether he or she moves or not (in other words, if the person seeks new ways of thinking of one same subject perspective); and (iii) the number of people inside the capsule (which would mean whether a scientist works on his or her own ${ }^{8}$ or as part of a group) (Figure 2).

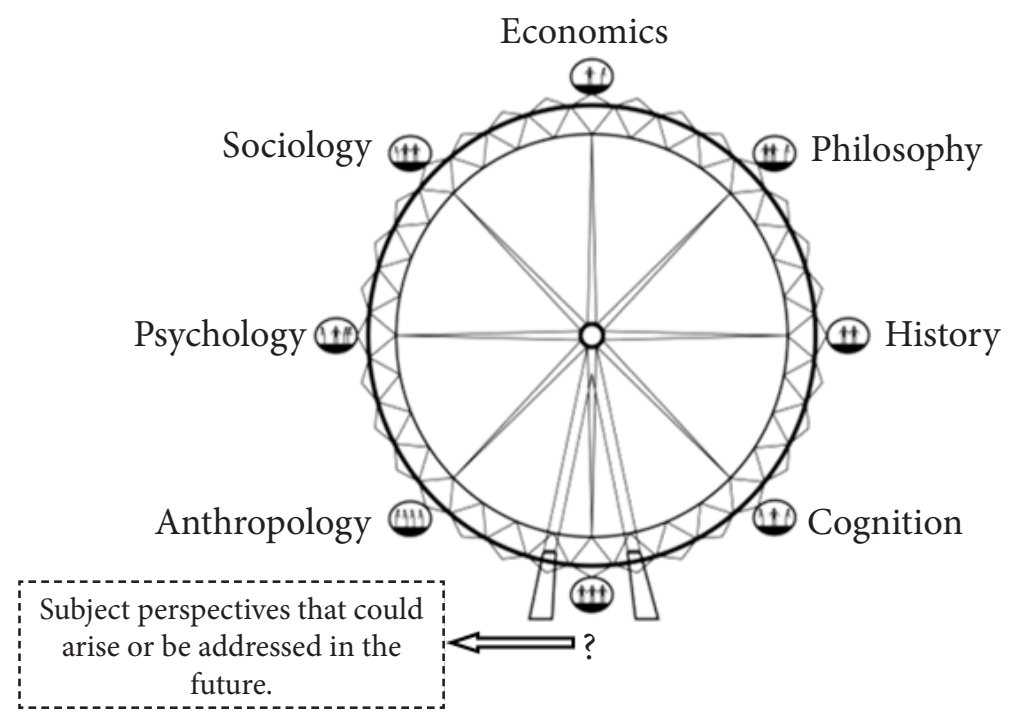

Figure 1. Science Eye - Visual representation of MoSSE adapted from Justi and Erduran (2015, p. 7)

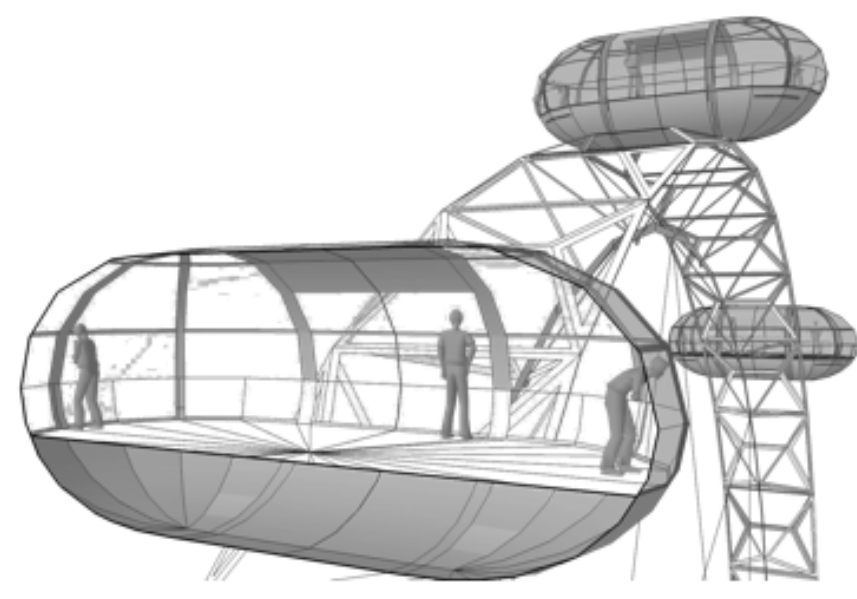

Figure 2. Different numbers of people within the capsules of the Science Eye representing distinct visions in certain disciplinary perspectives (Justi \& Erduran, 2015, p. 8)

In Figure 1, there is also a question mark linked to one of the capsules, showing that one or more disciplinary perspectives could emerge or be addressed in specific contexts, showing that the model is open to modifications. Therefore, the intention of the authors on showing these disciplinary perspectives was not that they should be exhaustive, but rather should be representative.

8 Such an aspect is emphasised in the model because the idea that scientists work alone is very common among students and teachers. 
The main aim shown by the authors in basing discussions with Science teachers about Science on MoSSE is that they could use it as support when planning more authentic teaching situations. They also highlight that, because of the possible existence of divergent viewpoints for each of the subject perspectives, it is possible that, at appropriate moments and within appropriate contexts, the teacher may address these, thus favouring the development of a wider view about Science among the students.

In addition, regarding MoSSE as a form of support in planning more authentic teaching situations, the authors mention that the model does not suggest that all characteristics related to all subject perspectives should be discussed with the students at only one moment. Much to the contrary, they say that one of the roles of the teacher is to decide which characteristics, of which subject perspectives, shall be addressed (or not) within the teaching of a certain curricular scientific content, within a given educational context. This is because, just like Allchin (2011, 2013, 2017), Justi and Erduran (2015) also defend the view that aspects of NOS should be introduced in a contextualised, explicit, and integrated manner.

As we see it, this model does have some advantages compared to the other proposals as previously presented and discussed. Among these advantages, we highlight that (i) it brings an ample view of Science on explicitly highlighting many subject perspectives as relevant thereto; and (ii) it tends to be understood by teachers, as it uses an explicitly analogue representation in which its main characteristics can easily be perceived. On the other hand, we have also noticed that, as happens in other proposals, the characterisation of these subject proposals is restricted to a definition of each one of them, which may not favour the teachers' understanding of its meanings, leading to the ultimate aim not being fully achieved. From there came forth our main motivation to expand the model.

At the same time, considering the potential of MoSSE as support for teachers when planning more authentic teaching situations, we conclude that it would be interesting if the model could also be used as a tool for analysis of data obtained from teaching contexts in which teachers have already used it. For this, it was essential to expand the scope of the characterisation of subject perspectives. This means that the main question that motivated this research was: how to expand the Model of Science for Science Education seeking its use both as support for the introduction of aspects of Nature of Science in teaching contexts and as a tool for analysis of data collected in such contexts?

\section{Methodological Issues}

To provide grounds for the discussion of this research issue, first we reviewed the specialised literature from different areas of knowledge, so that, from that point on, we could recognise the limits and scope of each of the subject perspectives as present in MoSSE (Figure 1). For this, and in a move to favour the understanding of the model by the teacher (most importantly) and/or by the researcher, we have identified characteristics of each of the areas of knowledge, that allowed their clear and brief presentation, with 
the limitation of their objects of study, as well as the main aspects of NOS that they address, and contribute to characterise (as shown in the following section). We start with the area of Philosophy of Science due to its key central role, as Western Science started with the philosophers of Ancient Greece, the result of that being that, prior to being established as a specific area of its own, Science was part of Philosophy (as was also the case with other subjects or areas of knowledge' ${ }^{9}$ e.g., Biology, Physics, Geometry, Logic, Psychology (Rosenberg, 2005)).

However, areas that "separated" from Philosophy left it questions whose answers are beyond its scope. For instance, the fact that Mathematics works with numbers does not mean that it has answers to the main question what is a number? When we ask ourselves about the meaning of number, we are not referring to the meaning of each numerical representation. In this case, this is a wider question, that Mathematics itself does not answer, and does not strive to answer (Rosenberg, 2005).

Therefore, Philosophy is essential to Science, as it can help with the understanding of other areas, allowing a wider look (a "philosophic" look) about each one of them. In addition, according to Rosenberg (2005), issues about Science, meaning those that involve characteristics, limits and scope of their objects and methods of study, are questions that both scientists and philosophers can answer. Also according to Rosenberg (2005), the "reflection on the way contemporary scientific findings and theories influence philosophy shows that each is indispensable for understanding the other" (p. 1). Within this perspective, the large area of Philosophy is an essential prior requirement for the understanding of other areas such as Philosophy of Science, Psychology of Science, Anthropology of Science, Sociology of Science, Economics of Science, History of Science, among others.

This means that Philosophy is a complex area and, as such, it is difficult to characterise in an easy way, as its aspects could be present (explicit or implicitly) in all other areas, meaning that Philosophy dialogues with other areas. In this regard, we proposed changes to the MoSSE so that Philosophy could be understood both as an area of knowledge in its own right (Philosophy of Science) and as a "philosophical base" for other areas. On using the expression "philosophical base" we are considering a meaning for the term "base" like that used with the meaning of support or foundations, often not visible. We therefore accept the dialogue (explicit or implicit) between Philosophy and other areas. In addition, the proposal of the "philosophical base" element also solves a problem identified in a later empirical work. Lima (2017) tried to identify the content knowledge of NOS as shown by pre-service teachers who participated in activities involving historical facts and controversies where aspects of NOS were made explicit. The author used the MoSSE as a theoretical background to sustain her analysis, but found difficulty to pinpoint the limits and define the scope of each disciplinary perspective,

9 We understand areas as being something wider in scope, such as Philosophy, Psychology, Anthropology, Sociology, Economics, and History. On the other hand, subjects would be more specific, as if parts of an area (e.g., Biology, Physics, Mathematics). 
thanks to the very presence of "elements of Philosophy" associated to these perspectives. On acknowledging the fact that elements from any of the disciplinary perspectives could be expressed based on a "philosophical look", we facilitate the categorisation of the data based on the model, as the categories derived from it become more clearly explicit.

Apart from this change, we have also replaced the term "disciplinary perspectives" which had been used by Justi and Erduran (2015) by "areas of knowledge", as we understand that this change helps to stress that each capsule of this model refers to a wider body of knowledge, with possible internal subdivisions, according to the perspectives assumed.

Next, we define what each of the areas of knowledge proposes to study; in other words, each area's limits and scope. For this, we analysed specific productions in some areas, seeking to characterise each of them and, at the same time, to identify and detail the meaning of their respective aspects of NOS. We therefore studied in detail specific references on which we have based ourselves in order to discuss them, such as in Philosophy of Science: Feist (2012), Feist and Gorman (1998), Osbeck et al. (2011), Shadish et al. (1994), Shadish et al. (1989); in Cognition of Science: Dunbar (2002), Dunbar and Blanchette (2001), Giere (1992, 1998, 2002); in Anthropology of Science: Knorr-Cetina (1999), Laraia (2001), Marcus and Fischer (1986), Pickering (1995); in Sociology of Science: Allchin (2004), Cunningham and Helms (1998), Latour (1987), Latour and Woolgar (1986); and in Economics of Science: Diamond Jr. (1996, 2008), Erduran and Mugaloglu (2013), Irzik (2013), Knuuttila (2013), Vermeir (2013).

Having made the readings related to the areas of Psychology and Cognition of Science, we integrate these areas, as the consideration of Cognition of Science as a subdivision of Psychology of Science is well aligned with the internal division of Psychology, arising from the difficulty to separate the different mental and behaviour processes in the individual. Thinking of proposing a second function for the model (as a data analysis tool), this integration makes it more functional due to the elimination of the difficulty to distinguish the two areas; in other words, making the categories more excludent.

Apart from the changes concerning the areas of Philosophy, Psychology, and Cognition of Science, we also not only present the characterisation of each area of knowledge, but also propose and didactically characterise aspects of NOS present therein. Such an action could facilitate the use of the expanded model for its original proposed purpose (support for teachers when planning more authentic teaching situations) and for the additional purpose as proposed in this article (as a data analysis tool). In addition, the consideration of aspects rather than just areas could contribute not only to teachers' better understanding of the meaning of each area and of what parts of NOS to introduce in Science teaching but also to make the expanded model functional for both these purposes, insofar as this means detailing the meaning of each area and each aspect (even in cases where an aspect with the same name - in full or in part - is present in more than one area). 
During the expansion of the model we have identified other aspects concerning each area, apart from those presented in the next section. However, we have decided not to include them in the new version of the model because these are very specific, and as they do not contribute to back up discussions in the area of Science Education.

Finally, in order to validate our model, it was discussed with the members of our Research Group (made up of researchers from different levels of teaching: undergraduates, professors, master's students, doctoral students, and academic doctors) and three researchers specialised in the area. As a result, some aspects of NOS were inserted or removed to make the characterisation of each area of knowledge clearer.

\section{Expansion of the Model of Science for Science Education}

- As discussed in the previous section, the expansion of MoSSE occurred based on the following events:

- Inclusion of the "philosophical base" element;

- Replacement of the old term "disciplinary perspectives" by the new terminology "areas of knowledge";

- Integration of the area Cognition of Science with the Psychology of Science area;

- Expansion of the meaning of the question mark in the analogue visual representation of the model;

- Characterisation of each area of knowledge;

- Proposal and characterisation of the aspects of NOS present in each of the areas of knowledge; and, consequently,

- Change to the analogue visual representation of the model.

All this was done considering the aims of this research - seeking to favour the use of the model as support for teachers in the planning of more authentic teaching situations, and as a data analysis tool - as both require more detail and greater clarity about the elements presented in the MoSSE.

As a result, this expansion resulted in what we have called the second version of the Model of Science for Science Education (MoSSE v.2) and whose visual representation is shown in Figure 3. 


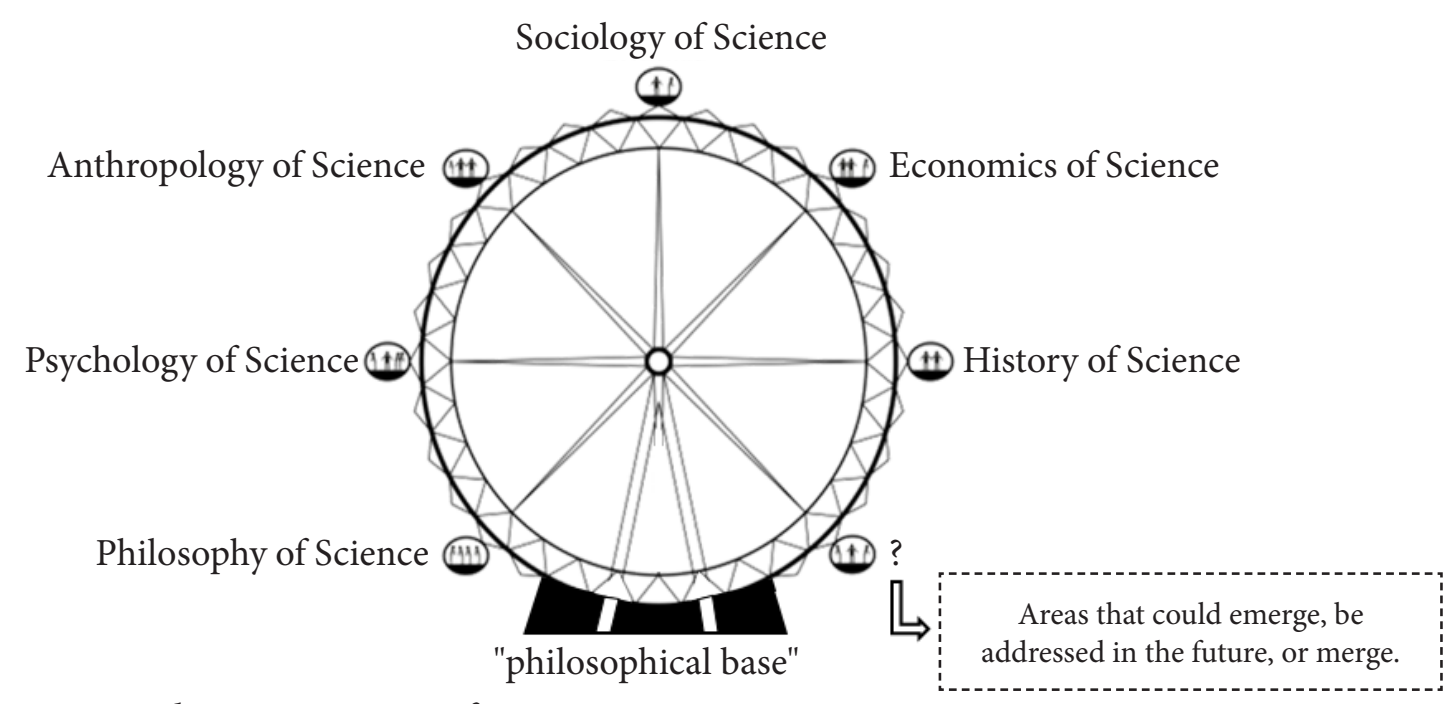

Figure 3. Visual representation of MoSSE v.2

When compared with Figure 1, Figure 3 shows that, in addition to both the inclusion of the new "philosophical base" element and the fact that Cognition of Science is not represented, we have expanded the meaning of the question mark.

Next, we present the characterisation of each area of knowledge, based on a summary of what each one proposes to study, which means its limits and scope, as also the identification and detailing of the meaning of their respective aspects of NOS (presented in alphabetical order, due to a lack of criteria for their ordering).

\section{Philosophy of Science}

This area studies what Science actually means. As a result, the main contributions of Philosophy of Science to the area of Science Education are questions that are specifically, but not exclusively, discussed by philosophers. These questions can be related to the origins, the goals and the natures of the areas of knowledge; the ethical and moral values present in each area; the criteria for the construction of scientific knowledge in each area, considering the necessary methodological rigour. Such questions can also be related to the processes for the construction of scientific knowledge in each of the areas, such as preparation, communication, evaluation, review and validation; and scientific and/or epistemic practices ${ }^{10}$ used in each one of them, such as investigation, experimentation, data analysis, modelling and argumentation, among others.

The study of Philosophy of Science includes the process for construction of scientific knowledge, as also some of its aspects:

- Epistemology: this presents a thought about the whole; in other words, about nature, objectives, values, criteria, scientific and epistemic processes and practices, therefore being an aspect that enables a thought about the limits

10 Following the views of Jiménez-Aleixandre and Duschl (2015), we understand scientific practice as those practices that establish scientific processes, but which do not necessarily result in the production of scientific knowledge. Epistemic practices, on the other hand, are taken as bring those that result in the production of scientific knowledge, which may or may not also be considered scientific. 
and the scopes related to the construction of scientific knowledge;

- Ethics: this discusses the ethical and moral values that guide scientific and/ or epistemic practices or are grounds for decisions made in the area of knowledge; and

- Logic: this discusses ways of thinking and the reasoning related to the construction of scientific knowledge.

It is important to highlight that, as the area of Philosophy of Science is the widest in scope when compared to the other areas of knowledge, then so are its aspects. For this reason, to have a distant look on the paths trailed during the process of construction of scientific knowledge, it is also necessary to develop a "philosophic eye". Therefore, as mentioned in the previous section, these aspects can be observed explicitly or implicitly in other areas, as a result of the existence of the "philosophical base" element, included in the current version of the model.

\section{Psychology of Science}

This is an area that studies mental processes and the behaviour of the individual person $^{11}$, in this case the scientist, during the processes for the production and use of scientific knowledge. Focusing specifically on the mental processes studied within the perspective of Cognitive Psychology, MoSSE v.2 focuses on the processes for the acquisition of knowledge; in other words, how an individual person thinks during production and use of scientific knowledge. Such mental processes are often indissociable from the behaviour of the individual person and other mental aspects as studied by other subdivisions of Psychology, such as Psychoanalysis. For this reason, different from the view taken by Justi and Erduran (2015), we have decided to include aspects regarding Cognition in this area.

Considering that the study of Psychology of Science includes intrapersonal relations of an individual person (scientist) with the processes for production and use of scientific knowledge, some of its aspects are:

- Complexity: This issue discusses how, during the processes for production and use of scientific content, a scientist can have difficulty to understand part thereof, due to its complexity;

- Creativity: This discusses the capacity that a scientist has to create, produce, and/or invent something new, as also to innovate based on something that already exists, during the processes of production and use of certain scientific content;

- Fallibility: This discusses how each scientist identifies and deals with errors during the process for production and use of scientific content;

- Uncertainty: This item discusses how each scientist deals with uncertainties ${ }^{12}$, and more precisely how the scientist gains awareness, then takes a stand and,

11 This focus on the individual distinguishes Psychology of Science from Sociology of Science, as this latter area focuses on the interaction between individual people, within society.

12 We understand uncertainty as something for which we cannot accurately predict a result or come up with an explanation. 
when possible or when necessary, takes decisions when faced with these uncertainties;

- Motivational influence: This discusses the influences that the motivations of a scientist, be they intrinsic and/or extrinsic, may suffer and/or exercise on the processes for production and use of scientific knowledge;

- Intelligence: Discusses intellectual characteristics of a scientist, linking it to the way the scientist understands, connects, and makes choices concerning a certain type of scientific knowledge during the processes for the production and use thereof, so that it may be possible to think of the scientist as having "regular" intelligence, meaning that the scientist does not have an intelligence that is out of the ordinary (which would make him or her a genius);

- Limitation: Discusses how, due to internal and/or external factors, a scientist could experience difficulties, or even see himself or herself unable to continue with the process of production and use of certain scientific knowledge;

- Non-linearity of reasoning: Discusses how a scientist's thinking does not undergo linear change during the processes for production and use of scientific knowledge;

- Objectivity: Discusses how a scientist can think and act directly, meaning being focused on a target during the processes of production and use of scientific knowledge;

- Personality: Discusses the personality ${ }^{13}$ of a scientist, seeking to explain, for example, the behaviour thereof in a certain situation, throughout the processes for production and use of scientific knowledge;

- Rationality: Discusses how a scientist can think and act based on reason; in other words, how he or she can connect thoughts following some logic, during the processes for production and use of scientific knowledge;

- Representation: Discusses the scientist's ability to express an idea, be it verbally, visually, mathematically or in another way (for example, on thinking of and/ or producing analogies and models during the processes for production and use of scientific knowledge);

- Subjectivity: Discusses how the scientist's ways of thinking and/or acting are related to his or her own pre-conceptions, which could be different from those of another person and not necessarily based on some kind of explicit logic.

In this area in particular, it is relevant to make an observation on three aspects: Objectivity, Rationality and Subjectivity. This is due to the current context we are now living, known as the post-truth era, which means times when individuals resort to emotions and personal beliefs instead of objective facts to mould public opinion (Oxford Dictionary, 2016) and that, therefore, can be regarded as an uninformed or acritical type of public opinion. In this context, where individual people tend to have extreme views, such aspects are very important

13 We understand personality as a set of significant characteristics, specific to an individual, and that identify this individual, distinguishing him or her from others. This includes, for example, if the person is honest or incorruptible in a certain situation, during the processes for production and use of scientific knowledge. 
so that they may seek a posture that is present in a kind of continuum ${ }^{14}$. This is because, for an individual who takes on an extremist position, Science is either rational or subjective. In other words, for this individual person the aspects are represented as: Objectivity and Rationality versus Subjectivity, meaning that, if there is acknowledgement of the presence of subjectivity in the construction of Science, its status and credibility are reduced (as discussed, for instance, by El-Hani \& Machado, 2020; Martins, 2015). From this standpoint, if we identify these three aspects in one same area of knowledge, and if we characterise each one of these, then we have the intention of contributing so that individual people may understand them and also reflect upon them, so that then, starting from this, they may be able to take up a posture in a kind of continuum instead of just one extreme, or the other, of this continuum.

This same logic was followed with regard to the aspects of Motivational influence, Cultural influence, Socio-political influence and Historical influence ${ }^{15}$, which means that, based on these aspects, it is possible that the individuals become aware of the fact that Science is not neutral, meaning that it influences, and is influenced by, different aspects (as discussed in El-Hani \& Machado, 2020). This would be an important contribution not only for the area of Science Education as also for society as a whole, as the adoption of extreme positions by individual people is something historical that, in bygone days, was influenced, for example, by religion, and now, in the post-truth era, is being (particularly) influenced by politics (Neiva, 2020). In this way, it is essential that we promote a more authentic type of scientific education and, as a result, a process of scientific literacy that is wider in scope, seeking the development of a well-informed and critical style of public opinion.

\section{Anthropology of Science}

Anthropology is an area that studies the human being in a broader sense, in the sense of humanity itself. This area can be subdivided ${ }^{16}$ as follows: (i) Biological or Physical Anthropology, which studies the human being in its biological dimension, including mankind's origins, evolution, and physical variations; (ii) Social ${ }^{17}$ or Cultural ${ }^{18}$ Anthropology, which studies the human being and different cultures, which means, in essence, the cultural diversity of mankind; (iii) Linguistic Anthropology, that studies mankind and language (language, speech, and linguistic issues), as well

\footnotetext{
14 We assume that the representation (or an attempt at representation) of a balance between the extremes as a continuum.

15 These last three are characterised in the following sections.

16 These subdivisions may differ depending on the origin of the authors who propose them: Latin America, the United States of America, or Europe. For this reason, when necessary, for a better understanding of our ideas, we decide to present the different forms under which these subdivisions may appear, as also the relationships between them.

17 Social Anthropology is different from Sociology with regard to its object of investigation. Sociology studies the human species as society, while Social Anthropology studies the influence of this society upon humanity.

18 US authors only use the term Cultural Anthropology, as they feel that Social Anthropology and Cultural Anthropology are distinct areas. In the US view, Cultural Anthropology Cultural studies human cultural diversity, among both extinct and contemporary groups. This is different from Social Anthropology as the concept of society is wider in scope than that of culture, as a society can consist of individuals who show signs of different cultures.
} 
as the consequences and shades involved in human language; and (iv) Archaeological Anthropology, that studies the man of past and present, based on an analysis of material remains such as fossils, paintings, works of art and architecture, interventions in the environment. In this way, each subdivision has specific questions attached to it and, even though ethnography is a methodology widely used in the area of Anthropology, each subdivision also makes use of specific methods (thus making it clear that there is not "the" or "an only" method), with the study of the human being common to all these.

Apart from studying the human being, Anthropology of Science also studies the relationship between the human being and scientific knowledge, considering that the production of this knowledge is a type of social action, and that its development is a type of cultural production. This being the case, we assume that the study of Anthropology of Science is linked to the processes of production and development of scientific content based on aspects such as:

- Incommensurability: Discusses the concept of culture ${ }^{19}$, so that such discussions lead to the ideas that there is no good or bad culture, and neither a better or a worse culture; there are just different cultures. Therefore, the same scientific knowledge may be constructed, interpreted and valued in different ways, according to different cultures; and

- Cultural influence: Discusses the influences ${ }^{20}$ that culture may have and/or exercise in relation to certain scientific knowledge. This means that individual people who express different cultures can interpret a same phenomenon in different ways.

\section{Sociology of Science}

This is an area which looks into how the process of production of scientific knowledge unfolds, analysing the interactions of the individual person, in this case the scientist, within society. Therefore, the studies of this area show that Science is a social practice, involving aspects such as:

- Acceptability: Discusses how knowledge is produced, communicated, evaluated, reviewed and validated by scientists, so that it is accepted as scientific.

- Credibility: Discusses the status that the scientists, the institutions, the prizes and awards (like the Nobel prize) and/or Science itself have vis-à-vis the scientific community and/or society as a whole;

- Fallibility: Discusses how scientists identify and deal with mistakes during the process for production of scientific knowledge, in a social perspective, or, in other words, how they team up in the academic community when faced with

19 We understand culture as being a set of beliefs, habits, ways of dressing, ways of thinking and acting, speaking, eating habits, walking habits and styles of praying, among others, meaning what is passed, acquired, learnt, experienced and shared with individual people (Laraia, 2001).

20 Arising, for example, from positions related to the degrading of the environment, racism, and feminism, among others. 
mistakes, either their own or committed by other scientist(s);

- Uncertainty: Discusses how scientists, as a group of professional people, deal with uncertainties, and more precisely how they acquire awareness and take up a position, and also, when possible or necessary, take decisions regarding the group;

- Socio-political influence: Discusses the influence that the society in which the scientists find themselves and the (local or global) politics can suffer and/ or exercise during the process of production of scientific knowledge. For instance, Sociology of Science can discuss how social and political issues illuminated by different positions can have an influence on the development of research studies about a certain issue and/or how research as carried out interferes with the social and political medium; and

- Interaction among scientists: Discusses the different types of interaction among scientists, including partnerships, contributions, disagreements, and disputes, during the process of production of scientific knowledge.

\section{Economics of Science}

This is an area that studies the impact suffered and/or exercised through commodification $^{21}$ and commercialisation ${ }^{22}$ of scientific knowledge in the stages of production, development, and application thereof, as also some of its aspects:

- Access to knowledge: This discusses the issue of exclusivity of access to scientific knowledge and the implications this has on the monetary value added thereto, as well as implications regarding who can directly or indirectly make use of such knowledge;

- Applicability: This discusses the interest on the part of institutions involved in the processes of production, development and/or application of scientific knowledge in the use thereof;

- Competitiveness: This discusses competitivity between institutions during the processes for the production, development and application of scientific knowledge, seeking to obtain patents and/or recognition for the innovation;

- Funding sources: Addresses the variety of institutions, these including universities, research centres, industrial laboratories, Government agencies, and spin-off ${ }^{23}$ companies, among others, responsible for the funding of scientific research;

- Economic investment: Focuses on how investment, during the processes for production, development and application of scientific knowledge, is gradual and depends both on the results of these processes as on social, political, and environmental factors, among others;

21 Commodification is transforming something into merchandise (Knuuttila, 2013).

22 Commercialisation is putting something up for sale (Knuuttila, 2013).

23 Spin-off is a company derived from an original one. 
- Productivity: Discusses institutions' interests that are involved in the processes of production, development, and application of scientific knowledge in productivity, in terms of financial return;

- Advertising: Focuses on the interests of the institutions involved in processes of production, development and application of scientific knowledge, for the publicity thereof, with the ultimate goal of obtaining funding and/or commodification and commercialisation; and

- Feasibility: Discusses the evaluation process to define and/or justify investment in scientific research.

\section{History of Science}

This is an area that studies the development of scientific knowledge over time, which means the modification of the ideas related to Science and the production and/or modification of the ideas in past and/or contemporary contexts. Therefore, we believe that its main aspects are:

- Historical influence: This looks at the influences that the historical context may suffer and/or exercise, with regard to the processes for production and use of certain scientific knowledge over time;

- Multiplicity: Focuses on the different types of narratives and/or interpretations for one same historical episode, in relation to a certain item of scientific knowledge;

- Non-linearity: This aspect addresses the fact that there is not just one path for the development of scientific knowledge, including the recall of ideas presented in previous research studies, unforeseen circumstances, and changes in research into a certain piece of scientific knowledge, as unfolded over time.

- Progressivity: This discusses the process through which a certain piece of scientific knowledge is produced, communicated, assessed, revised and validated, gradually over time. It is therefore made evident that knowledge is not constructed in one go, requiring a certain period of time as necessary so that the processes for production of scientific knowledge may occur; and

- Tentativeness: This discusses the occurrence of changes to a certain unit of scientific knowledge over time, with some ideas being abandoned and replaced by new constructions, which is a consequence of the process being dynamic rather than linear and progressive.

\section{Expanding the Analogy}

Going back to the analogy with the London Eye (Figure 1), on proposing and characterising the aspects of NOS present in each of the areas of knowledge, we see the possibility of extension thereof. According to Justi and Erduran (2015), Science can be seen based on one single capsule (from the viewpoint of an individual person inside one 
of them) or several at the same time (from the viewpoint of an external observer). In the analogue visual representation for MoSSE v.2 (Figure 3), Science can still be visualised based either on one capsule or on many at the same time. However, in addition, it can also be viewed based on the integration of the "philosophical base" with one or more of the areas of knowledge (represented by capsules), for example, when a certain capsule (Philosophy, Psychology, Anthropology, Sociology, Economics, or History of Science) passes through the "philosophical base" of the Ferris wheel, making the "philosophical air" enter inside it and permeate the views of the individuals who are in that capsule or those who observe it from outside.

Also with regard to the visual representation for MoSSE v.2 (Figure 3), we perceive the possibility of extending the analogy with regard to the position taken up by the individual within the capsule. For instance, the Influence aspect (specified as motivational, cultural, socio-political and historical) appears in many of the areas represented by the capsules. In the original source domain, the individual person enters a capsule to see London from different angles. Then, if someone takes up a position within each capsule at a specific angle, then he or she can see London from the perspective of that particular angle. Returning to the analogue domain, this individual can gain a specific view of Science from the standpoint of the area represented by the capsule where the person is, and from the angle of where he would be positioned within that capsule (for example, from the perspective of the area of History of Science and under the angle represented by the Historical influence aspect, or from the perspective of the area of Psychology of Science and under the angle of the Motivational influence aspect.

This extension may not be generalised for all aspects of NOS, as only some of them have similar meanings (represented by names that are exactly the same or very similar). This backs up our belief that Science is integrated and wide in scope. However, for this integration to be possible, one must be clear about the existence of many forms of Science and that these have characteristics that could be shared with other forms of Science, as well as characteristics specific to each one of them (as discussed by Irzik and Nola, 2011, 2014).

Finally, just like Justi and Erduran (2015), we consider the criticism that has been raised against the lists of tenets and have based ourselves on the proposal raised by Allchin $(2011,2012 \mathrm{~b}, 2013)$ to propose our ideas. In addition, we have also based ourselves on the proposal of Erduran and Dagher (2014) to expand the scope of MoSSE, producing MoSSE v.2. This, because such proposals help to solve some of the many different problems that the ideas presented in lists of tenets bring. However, as formerly mentioned, MoSSE v.2 is justified as it presents detailed and didactic characterisation of what each of the aspects of NOS to be introduced into Science teaching would be like, as also provides a visual representation that favours understanding, especially by teachers. Thus, our main contribution refers to the dimension concerning what to teach about Science (according to Martins, 2015). Because of this, the use of MoSSE v.2 may help to promote a more authentic type of Science education, emancipatory as a result, 
to the extent that it can support the formation of people who are critical with reflexive minds (Sasseron \& Carvalho, 2011), meaning the development of a wider viewpoint about Science and, therefore, a critical and well-informed public opinion.

\section{Potentialities and Perspectives}

In a move to discuss the potential of MoSSE v.2, to begin with we decided to present a synthetic organisation of the different areas of knowledge represented in the model, and of their respective aspects of NOS (Figure 4). In this way, the reader may more easily identify which aspects are present in each area and which appear in more than one area (aspect identified by a name totally or partly the same in different areas).

\begin{tabular}{|c|c|c|c|c|c|c|}
\hline $\begin{array}{l}\text { Areas of } \\
\text { Knowledge }\end{array}$ & \multirow{2}{*}{$\begin{array}{l}\text { Philosophy } \\
\text { of Science }\end{array}$} & \multirow{2}{*}{$\begin{array}{l}\text { Psychology } \\
\text { of Science }\end{array}$} & \multirow{2}{*}{$\begin{array}{c}\text { Anthropology } \\
\text { of Science }\end{array}$} & \multirow{2}{*}{$\begin{array}{l}\text { Sociology } \\
\text { of Science }\end{array}$} & \multirow{2}{*}{$\begin{array}{l}\text { Economics } \\
\text { of Science }\end{array}$} & \multirow{2}{*}{$\begin{array}{l}\text { History } \\
\text { of Science }\end{array}$} \\
\hline Aspects of NOS & & & & & & \\
\hline Epistemology & $\mathrm{x}$ & & & & & \\
\hline Ethics & $\mathrm{x}$ & & & & & \\
\hline Logic & $\mathrm{x}$ & & & & & \\
\hline Complexity & & $\mathrm{X}$ & & & & \\
\hline Creativity & & $\mathrm{X}$ & & & & \\
\hline Fallibility & & $\mathrm{x}$ & & $\mathrm{x}$ & & \\
\hline Uncertainty & & $\mathrm{x}$ & & $\mathrm{x}$ & & \\
\hline Influence & & motivational & cultural & socio-political & & historical \\
\hline Intelligence & & $\mathrm{x}$ & & & & \\
\hline Limitation & & $\mathrm{x}$ & & & & \\
\hline Non-linearity & & of reasoning & & & & $\mathrm{x}$ \\
\hline Objectivity & & $\mathrm{x}$ & & & & \\
\hline Personality & & $\mathrm{x}$ & & & & \\
\hline Rationality & & $\mathrm{x}$ & & & & \\
\hline Representation & & $\mathrm{x}$ & & & & \\
\hline Subjectivity & & $\mathrm{X}$ & & & & \\
\hline Incommensurability & & & $\mathrm{x}$ & & & \\
\hline Acceptability & & & & $\mathrm{x}$ & & \\
\hline Credibility & & & & $\mathrm{x}$ & & \\
\hline $\begin{array}{l}\text { Interaction among } \\
\text { scientists }\end{array}$ & & & & $\mathrm{x}$ & & \\
\hline $\begin{array}{l}\text { Access to } \\
\text { knowledge }\end{array}$ & & & & & $\mathrm{x}$ & \\
\hline Applicability & & & & & $\mathrm{x}$ & \\
\hline Competitiveness & & & & & $\mathrm{x}$ & \\
\hline Funding sources & & & & & $\mathrm{x}$ & \\
\hline
\end{tabular}

Figure 4. A synthetic organisation of areas of knowledge as represented in MoSSE v.2 and their respective aspects (to be continued) 


\begin{tabular}{|l|l|l|l|l|l|c|}
\hline $\begin{array}{l}\text { Areas of } \\
\text { Knowledge }\end{array}$ & $\begin{array}{l}\text { Philosophy } \\
\text { of Science }\end{array}$ & $\begin{array}{c}\text { Psychology } \\
\text { of Science }\end{array}$ & $\begin{array}{l}\text { Anthropology } \\
\text { of Science }\end{array}$ & $\begin{array}{l}\text { Sociology } \\
\text { of Science }\end{array}$ & $\begin{array}{l}\text { Economics } \\
\text { of Science }\end{array}$ & $\begin{array}{c}\text { History } \\
\text { of Science }\end{array}$ \\
\hline Aspects of NOS & & & & $\mathrm{x}$ & \\
\hline $\begin{array}{l}\text { Economic } \\
\text { investment }\end{array}$ & & & & & $\mathrm{x}$ & \\
\hline Productivity & & & & & $\mathrm{x}$ & \\
\hline Advertising & & & & & & $\mathrm{x}$ \\
\hline Feasibility & & & & & & $\mathrm{x}$ \\
\hline Multiplicity & & & & & & $\mathrm{x}$ \\
\hline Progressivity & & & & & & \\
\hline Tentativeness & & & & & & \\
\hline
\end{tabular}

Figure 4. A synthetic organisation of areas of knowledge as represented in MoSSE v.2 and their respective aspects (continuation)

We also stress that, just like Justi and Erduran (2015) on presenting the different subject perspectives, our intention on proposing, characterising and presenting these aspects of NOS is not that they should be exhaustive, but that they be representative of the different aspects that can be related to different areas of knowledge within the context of Science Education.

Figure 4 shows that MoSSE v.2 characterises Science based on six main areas of knowledge, that are associated to 37 aspects of NOS, with three related to Philosophy of Science; 13 to Psychology of Science; two to Anthropology of Science; six to Sociology of Science; eight to Economics of Science; and five to History of Science. Some of these aspects are common to more than one area, such as the Fallibility and Uncertainty aspects that are common to Psychology and Sociology of Science. Apart from these, we also have the aspect of Non-linearity (with complements) which is common to Psychology and History of Science. Finally, we have the Influence aspect (with variations) which is common to the areas of Psychology, Anthropology, Sociology, and History of Science. However, even though the names of the aspects are the same (in full or in part), they represent different perspectives in each area of knowledge, thereby representing a different standpoint in the model. Along these same lines, considering the presence of the "philosophical base" element, the aspects of the area of Philosophy of Science, especially Ethics, permeate all the other areas. This means that Figure 4 favours the visualisation of the concept of Science as shown in MoSSE v.2.

With regard to the use of MoSSE v.2 as support for teachers planning more authentic teaching situations, having understood the meaning and significance of each aspect of NOS, the teacher can, based on Figure 4, more easily identify which aspects he or she wishes to introduce, and related to which areas, in a contextualised, explicit, and integrated manner, within an activity. However, the sheer number of areas of knowledge and aspects of NOS that could be inserted and discussed within a teaching context shall depend on the context in which the students are inserted, the activity, and information contained therein, the prior ideas that the students can state and/or research at the 
moment, and the goals of the teacher for that context of private teaching.

In this regard, by way of example, MoSSE v.2 has already been used as a theoretical background to propose activities based on the film The Boy Who Harnessed the Wind ${ }^{24}$ aimed at High School students, seeking to introduce aspects of NOS, in a contextualised, explicit, and integrated manner, within Science teaching (Siqueira, 2019). For the preparation of one of the activities, the author/teacher selected some excerpts of the film in which aspects of NOS, according to the details of their meanings as presented in the model, could be identified in the words and the actions of the characters. For instance, Excerpt 1, that Siqueira (2019) named as Curiosity of William ${ }^{25}$, shows the boy's curiosity on comparing the internal "skeleton" of the radio equipment owned by his father, equipment that worked perfectly, with the radio owned by his neighbour and which didn't work. In addition, this excerpt showed that the boy insisted for days on end, repairing the radio, until he managed it. Based on this excerpt, it is possible to insert and discuss, in a contextualized and explicit manner, the Creativity and Personality aspects, both from the Psychology of Science area. On the other hand, one can only say that this was done in an integrated manner on presenting and analysing the activity as a whole, as only after the combination of excerpts is it possible to discuss some curricular contents of Physics related to the production of energy (wind energy, in the case of the film).

Because of this, and thinking of the context of Basic Education, the names, the meanings and the respective areas of the aspects of NOS, as also the analogue visual representation of MoSSE v.2, are presented didactically, with the aim of helping the teacher with the elaboration and guidance of teaching activities. Otherwise, the model would be reduced to just a list of aspects of NOS that could be presented to the students in a declarative manner, something strongly criticised in specialised literature (e.g., Allchin, 2011, 2013, 2017; Erduran \& Dagher, 2014; Irzik \& Nola, 2011, 2014; Justi \& Erduran, 2015; Matthews, 2012; McComas, 2008; Nielsen, 2013; Osborne et al., 2003; van Dijk, 2011; Weinstein, 2008; Wong \& Hodson, 2010). However, we must point out that, at the moment of discussion of the activities, the teacher must not present the names, meanings, or respective areas of the aspects of NOS to the students, but rather the ideas related thereto (and relationships between them) if these are not mentioned by the students themselves.

With regard to the context of Higher Education, thinking about teacher qualification (initial and/or ongoing), the use of the model would be different. The names, the meanings, and the respective areas of the aspects of NOS not only can but should be presented to the (future) teachers, to expand their own knowledge and so they may be able to use this model as support when planning more authentic teaching situations with propriety. However, we suggest that, before the teachers are informed about MoSSE v.2, they should experience activities based on it so that, as discussed above,

$24 \mathrm{https} / /$ www.netflix.com/br/title/80200047

25 William is the protagonist of the film. 
the formative process may not be based on a declarative teaching style. In addition, we feel it is essential that teachers believe in the importance of promoting a more authentic type of Science education and insert this in their goals for the teaching and learning processes. For this reason, we are currently conducting a study that makes use of MoSSE v. 2 as foundations for the preparation of different types of activities (investigative, historical and argumentative), involving different contexts (daily routine, scientific, and socioscientific) aimed at educating pre-service Chemistry teachers. This, because the fact that they experience activities that support this perspective of education may help them to believe in the potential of, and promote, a more authentic style of Science education.

Regarding the use of MoSSE v.2 as an analytical tool for data collected in teaching contexts, based on the understanding of the elements presented in Figure 4, the analyst may more easily identify which aspects of NOS, and related to which areas of knowledge, were shown and/or experienced by the research subjects. In addition, if such data is analysed for a certain period of time, the analyst may have elements to understand the process of construction and development of scientific knowledge by the subjects involved. However, for the tool to be appropriately used, the cutting and/or analysis unit should not be made up of fragmented data. Even if the analyst is interested in using the tool for specific fragments, such as in transcription of speech, it is necessary that this be situated, which means inserted in the context from where it was proffered. It is therefore essential that one knows exactly what happened or what was said both before and after the transcribed section to be analysed. In this regard, we recommend to the analyst that, before using the tool, he or she should describe its data, and that the transcriptions should be situated within this description. This was done on analysing data collected in a teaching context with the aim of understanding views about Science as shown by High School students and any relations between these and Modelling-based Teaching in routine, scientific and socioscientific contexts (Santos, 2019).

Within this perspective, the aspects of NOS could be used by the analyst as welldefined categories, on analysis of the data collected in any teaching contexts. For this reason, we show concern with giving a name to, and presenting detailed characteristics of, each and every one of the aspects as identified and proposed, related to the respective areas of knowledge represented on MoSSE v.2. In addition, we feel this has been the most significant contribution made by this research to the area of Science Education. This, because we often find the term "aspects" and/or "aspects of NOS" in the Science Education literature, without these being identified and without clear explanation of their meanings. It is also common to find, for example, that certain information is linked to economic or historical aspects, among others. However, so far (start of 2020), we have not found, in the literature, any study that identifies and characterises such aspects, as well as establishing this general connection.

In this regard, MoSSE v. 2 is being used to analyse data collected within a teaching context of qualification of Chemistry teachers with the purpose of understanding: (i) the views about Science of the pre-service teachers, and the connection between these and a 
subject that has been planned and given in a contextualised manner; and (ii) the content knowledge of NOS as used by the pre-service teachers during a formative process based on the model. In addition, in this same context, MoSSE v.2 shall also be used by the future teachers to analyse a teaching activity based on the model, as they have produced.

Turning now to the perspectives of MoSSE v.2, even though this is a theoretical paper, different from Justi and Erduran (2015), we have had some empirical support available for the expansion thereof. Because of this, as we explain, we also present examples and have discussions about the two functions with which the model may be used, we have been able to show examples of some studies either recently completed and/or in progress. However, this does not exclude the need to carry out new studies, with the presentation of possible questions to be investigated. For instance, in the current context marked by the pandemic (caused by the coronavirus SARS-CoV-2) that we are now experiencing, and the problems this has caused, it may never have been so explicit as now that there is a need for integration of different areas of knowledge so that someone may take a position with regard to certain problems, or even seek solutions for these problems. Following this viewpoint, the use of MoSSE v.2 in Science teaching could favour such integration. However, it would be necessary to have special studies to analyse if and how such integration is favoured, as well as studies about the education and the development of teachers so that they may be able to lead the teaching process based on the perspective as defended here.

We stress that, in all studies as mentioned as exemplification of the use of MoSSE v.2, the aspects of NOS were used as well-defined categories for the preparation of activities and/or data analysis in teaching contexts, more specifically for the identification of aspects that could be introduced in a contextualised, and/or explicit, and/or integrated manner, in the teaching of Science/Chemistry, regardless of the educational level. In addition, many of these studies were, and are, being conducted by teachers and researchers in addition to those involved in the expansion of the model that resulted in MoSSE v. 2 - these being subjects that could present their own evaluations about the scope and limitations of this new version of the model. In this regard, the results of these studies shall also be contributing for the validation thereof.

Finally, we highlight that, just like many new models as proposed throughout history, the MoSSE v.2 is based on assumptions made by other previous models (mainly, but not only, from the MoSSE), but has essence-related elements that are different ${ }^{26}$. This means that some important points distinguish the proposal made in this paper from the others, that other authors have presented. To start with, this is not just a list of tenets, as that presented by Lederman and collaborators. Much to the contrary, it is aligned with a viewpoint based on wide-scope and contemporary Science, like the models presented by Allchin (based on the idea of Whole Science) and by Irzik and Nola, and Erduran and Dagher (based on the idea of Family Resemblance, proposed by Wittgenstein). Our proposal going beyond these, in an attempt to characterise a

26 In terms of a Lakatosian research programme, we kept the hard core, but changed the protective belt. 
viewpoint to instrumentalise teachers to think of Science as a whole, attempting to guide understanding and reflections about its construction processes. In this way, MoSSE v.2 proposes to guide understanding and reflections about Science, turning one's eyes to how the different aspects of NOS characterise it, while also trying not to immobilise them. In addition, the multiplicity of areas of knowledge and aspects of NOS included in such a model makes it evident the very status of diversity and continuous construction of different shades of Science, as it forecasts the possibility of appearance (or consideration) of new areas and aspects.

Thus, even with regard to other perspectives that present a wide-scope and contemporary view of Science, the MoSSE v.2 has three essential characteristics that tend to strengthen its use in teaching contexts and in analysis of these: (i) it shows itself to be more didactic, as it seeks to guide the teacher's and/or the researcher's thoughts through the large areas of knowledge, and through the different aspects of NOS based on the due characterisation of each one of these; (ii) it is represented by an analogy that favours the understanding of the roles of, and relations between, the different areas of knowledge and their respective aspects; and (iii) it reflects the dynamism and multiplicity of Science.

Also with regard to the use of analogue representations to favour the understanding of a model by teachers, this was done previously, in a theoretical manner, by Erduran and Dagher (2014) and then empirically, in studies carried out in only one single context for data collection involving trainee teachers (Erduran \& Kaya, 2018; Kaya et al., 2019). However, as highlighted before, the representation used by these authors involves a source domain unfamiliar to many teachers and where not all the relations between the elements of the model are clearly represented. As a result, and in line with the principles that define conditions for the establishment of satisfactory analogies (e.g., in Gentner, 1989), we feel that it may not contribute to such a direct mapping between the two domains of the analogy (and the consequent viewing of the elements present in the model represented and the relationships between them) as occurs in the case of an analogy with a source domain like a ferris wheel. This justifies our concern not only with the expansion of the model itself, but also with the change in its visual representation and with the presentation of clear explanations related to them, seeking to contribute to the understanding by teachers and researchers who may one day use MoSSE v.2.

Thus, starting from the studies based on MoSSE v. 2 and the disclosure of the results arising therefrom, in the near future, we expect to promote critical reflections about how us, teachers and researchers, are contributing to the promotion and the attainment of a more authentic type of Science education - and, as a result, an emancipatory one, to the extent that it could contribute to the education of people who have critical and reflexive minds (Sasseron \& Carvalho, 2011) based on the development of a more ample viewpoint about Science and, therefore, a well-informed and critical public opinion on the part of students. At the same time, we hope that, on making a tour of the visual representation of MoSSE v.2, teachers and researchers can expand their viewpoints about Science, so 
that the ideas discussed in this paper, and also in other papers that report on studies currently under way, expand the perspectives regarding the introduction of aspects of NOS in Science Education, thereby nurturing growing dialogue between all the parties interested in this subject.

\section{Acknowledgments}

The authors would like to thank: the members of the REAGIR - Modelling and Science Education Research Group and the three researchers specialised in the area, for having contributed to the validation of MoSSE v.2; Izabella Martins, for her contribution in the production of the analogue visual representation of the model; CAPES and CNPq, for their financial backing which has allowed them to dedicate time to the conduction of this research study; and the RBPEC's anonymous reviewers and associate editor, Cristiano Moura, for their critical reading of the originally submitted version of this paper, and for their comments that have contributed to the production of this current version.

\section{References}

Abd-El-Khalick, F. (2012). Nature of Science in Science Education: Towards a coherent framework for synergistic research and development. In B. J. Fraser, K. G. Tobin, \& C. J. McRobbie (Eds.), Second International Handbook of Science Education (pp. 1041-1060). Springer.

Abd-El-Khalick, F., Bell, R. L., \& Lederman, N. G. (1998). The Nature of Science and Instructional Practice: Making the unnatural natural. Science Education, 82(4), 417-436. https://doi.org/10.1002/(SICI)1098-237X(199807)82:4\%3C417::AIDSCE1\%3E3.0.CO;2-E

Allchin, D. (2004). Should the Sociology of Science Be Rated X? Science Education, 86(6), 934-946. https://doi.org/910.1002/sce.20026

Allchin, D. (2011). Evaluating Knowledge of the Nature of (Whole) Science. Science Education, 95(3), 518-542. https://doi.org/510.1002/sce.20432

Allchin, D. (2012a). How Can History and Philosophy of Science Contribute to Understanding the Nature of Science for Scientific Literacy?: Mapping research needs. Paper presented at the Conference on How Can the HPS Contribute to Contemporary U.S., Boston, Massachusetts.

Allchin, D. (2012b). The Minnesota Case Study Collection: New Historical Inquiry Case Studies for Nature of Science Education. Science \& Education, 21(9), 1263-1281. https:// doi.org/10.1007/s11191-011-9368-X

Allchin, D. (2013). Teaching the Nature of Science: Perspectives \& Resources. SHiPS Educational Press. 
Allchin, D. (2014). From Science Studies to Scientific Literacy: A view from the classroom. Science \& Education, 23(9), 1911-1932. https://doi.org/10.1007/s11191-013-9672-8

Allchin, D. (2017). Beyond the Consensus View: Whole Science. Canadian Journal of Science, Mathematics and Technology Education, 17(1), 18-26. https://doi.org/10.1080/1 4926156.14922016.11271921

Allchin, D., Andersen, H. M., \& Nielsen, K. (2014). Complementary Approaches to Teaching Nature of Science: Integrating student inquiry, historical cases, and contemporary cases in classroom practice. Science Education, 98(3), 461-486. https:// doi.org/410.1002/sce.21111

Archer, L., DeWitt, J., Osborne, J., Dillon, J., Willis, B., \& Wong, B. (2010). "Doing” Science versus "Being" a Scientist: Examining 10-and 11-year-old schoolchildren's constructions of science through the lens of identity. Science Education, 94(4), 617-639. https://doi.org/610.1002/sce.20399

Bayir, E., Cakici, Y., \& Ertas, O. (2014). Exploring Natural and Social Scientists' Views of Nature of Science. International Journal of Science Education, 36(8), 1286-1312. https:// doi.org/1210.1080/09500693.09502013.09860496

Cakici, Y., \& Bayir, E. (2012). Developing Children's Views of the Nature of Science through Role Play. International Journal of Science Education, 34(7), 1075-1091. https:// doi.org/1010.1080/09500693.09502011.09647109

Carvalho, B., \& Justi, R. (2019). O Caso Histórico Marie Curie: Investigando o Potencial da História da Ciência para Favorecer Reflexões de Professores em Formação sobre Natureza da Ciência [The Marie Curie Historical Case: Studying the Potential of History of Science to Support Pre-service Teachers' Reflections on Nature of Science]. Alexandria: Revista de Educação em Ciência e Tecnologia, 12(1), 351-373. http://dx.doi. org/310.5007/1982-5153.2019v5012n5001p5351

Cunningham, C. M., \& Helms, J. V. (1998). Sociology of Science as a Means to a More Authentic, Inclusive Science Education. Journal of Research in Science Teaching, 35(5), $483-$ 499. https://doi.org/410.1002/(SICI)1098-2736(199805)199835:199805<199483::AIDTEA199802>199803.199800.CO;199802-L

Deng, F., Chen, D. T., Tsai, C. C., \& Chai, C. S. (2011). Students' Views of the Nature of Science: A critical review of research. Science Education, 95(6), 961-999. https://doi. org/910.1002/sce.20460

Diamond Jr, A. M. (1996). The Economics of Science. Knowledge and Policy: The International Journal of Knowledge Transfer and Utilization, 9(2-3), 6-49.

Diamond Jr, A. M. (2008). Economics of Science. In S. N. Durlauf \& E. Blume (Eds.), The New Palgrave Dictionary of Economics Online (pp. 1-27). Palgrave Macmillan.

Driver, R., Leach, J., Millar, R., \& Scott, P. (1996). Young people’s images of science. Open University Press. 
Dunbar, K. (2002). Understanding the Role of Cognition in Science: The science as category framework. In P. Carruthers, S. Stich, \& M. Siegal (Eds.), The Cognitive Basis of Science (pp. 154-170). Cambridge University Press.

Dunbar, K., \& Blanchette, I. (2001). The in Vivo/in Vitro Approach to Cognition: The case of analogy. Trends in Cognitive Sciences, 5(8), 334-339. https://doi.org/310.1016/ S1364-6613(1000)01698-01693

El-Hani, C. N., Machado, V. (2020). COVID-19: The need of an integrated and critical view. Ethnobiology and Conservation, 9(18), 1-20. https://doi.org/10.15451/ec2020-059.18-1-20

Erduran, S., \& Dagher, Z. R. (2014). Reconceptualising the Nature of Science for Science Education: Scientific knowledge, practices and other family categories. Springer.

Erduran, S., Dagher, Z. R., \& McDonald, C. V. (2019). Contributions of the Family Resemblance Approach to Nature of Science in Science Education: A Review of Emergent Research and Development. Science \& Education, 28(3-5), 311-328. https:// doi.org/10.1007/s11191-019-00052-2

Erduran, S., Kaya, E. (2018). Drawing Nature of Science in Pre-service Science Teacher Education: Epistemic Insight Through Visual Representations. Research in Science Education, 48, 1133-1149. https://doi.org/10.1007/s11165-018-9773-0

Erduran, S., \& Mugaloglu, E. (2013). Interactions of Economics of Science and Science Education: Investigating the implications for science teaching and learning. Science \& Education, 22(10), 2405-2425. https://doi.org/10.1007/s11191-012-9519-8

Feist, G. J. (2012). The Psychology of Science is Off and Running but Where do We Go from Here? In R. W. Proctor, \& E. J. Capaldi (Eds.), Psychology of Science: Implicit and Explicit Processes (pp. 13-39). Oxford University Press.

Feist, G. J., \& Gorman, M. E. (1998). The Psychology of Science: Review and integration of a nascent discipline. Review of General Psychology, 2(1), 3-47. https://doi. org/10.1037/1089-2680.1032.1031.1033

Gentner, D. (1989). The mechanisms of analogical learning. In S. Vosniadou \& A. Ortony (Eds.), Similarity and analogical reasoning (pp. 199-241). Cambridge University Press.

Giere, R. N. (1992). Cognitive Models of Science. University of Minnesota Press.

Giere, R. N. (1998). Explaining Science: A cognitive approach. University of Chicago Press.

Giere, R. N. (2002). Scientific Cognition as Distributed Cognition. In P. Carruthers, S. Stich, \& M. Siegal (Eds.), The Cognitive Basis of Science (pp. 285-299). Cambridge University Press. 
Gilbert, J. (2004). Models and Modelling: Routes to a more authentic science education. International Journal of Science and Mathematics Education, 2(2), 115-130. https://doi. org/110.1007/s10763-10004-13186-10764

Gilbert, J., \& Justi, R. (2016). Modelling-based Teaching in Science Education. Springer International Publishing.

Guerra-Ramos, M. T. (2012). Teachers' ideas about the nature of science: A critical analysis of research approaches and their contribution to pedagogical practice. Science \& Education, 21(5), 631-655. https://doi.org/10.1007/s11191-011-9395-7

Irzik, G. (2013). Introduction: Commercialization of academic science and a new agenda for science education. Science \& Education, 22(10), 2375-2384. https://doi.org/10.1007/ s11191-013-9583-8

Irzik, G., \& Nola, R. (2011). A Family Resemblance Approach to the Nature of Science for Science Education. Science \& Education, 20(7-8), 591-607. https://doi.org/10.1007/ s11191-010-9293-4

Irzik, G., \& Nola, R. (2014). New Directions for Nature of Science Research. In M. R. Matthews (Ed.), International Handbook of Research in History, Philosophy and Science Teaching (pp. 999-1021). Springer.

Jiménez-Aleixandre, M. P., \& Duschl, R. (2015). Epistemic Practices and Scientific Practices: Theoretical and Educational Challenges. Paper presented at the 11th Conference of the European Science Education Research Association, Helsinki, Finland.

Justi, R., Almeida, B., \& Santos, M. (2019). Scientific Literacy: Going Beyond DecisionMaking. Paper presented at the 13th Conference of the European Science Education Research Association, Bologna, Italy.

Justi, R., \& Erduran, S. (2015). Characterizing Nature of Science: A supporting model for teachers. Paper presented at the Conference of the International History, Philosophy, and Science Teaching Group, Rio de Janeiro, Brazil.

Justi, R., \& Santos, M. (2019). Students' Functional Understanding of Nature of Science: Contributions from a Film-based Teaching Activity. Paper presented at the 92nd Annual International Conference of the National Association for Research in Science Teaching, Baltimore, USA.

Kaya, E., \& Erduran, S. (2016). From FRA to RFN: How the Family Resemblance Approach Can Be Transformed for Science Curriculum Analysis on Nature of Science. Science \& Education, 25(9-10), 1115-1133. https://doi.org/10.1007/s11191-016-9861-3

Kaya, E., Erduran, S., Aksoza, B., \& Akgun, S. (2019). Reconceptualised family resemblance approach to nature of science in pre-service science teacher education. International Journal of Science Education, 41(1), 21-47. https://doi.org/10.1080/09500 693.09502018.01529447 
Knorr-Cetina, K. (1999). Epistemic Cultures: How the sciences make knowledge. Harvard University Press.

Knuuttila, T. (2013). Science in a New Mode: Good old (theoretical) science versus brave new (commodified) knowledge production? Science \& Education, 22(10), 2443-2461. https://doi.org/10.1007/s11191-012-9498-9

Laraia, R. B. (2001). Culture: An Anthropologica. Jorge Zahar.

Latour, B. (1987). Science in Action. Harvard University Press.

Latour, B., \& Woolgar, S. (1986). Laboratory Life: The construction of scientific facts. Princeton University Press.

Lederman, J. S., \& Khishfe, R. (2002). Views of Nature of Science, Form D. Unpublished paper. Illinois Institute of Technology.

Lederman, J. S., \& Ko, E. K. (2002). Views of Nature of Science, Form E. Unpublished paper. Illinois Institute of Technology.

Lederman, N. G. (2006). Syntax of Nature of Science within Inquiry and Science Instruction. In L. B. Flick \& N. G. Lederman (Eds.), Scientific Inquiry and Nature of Science (pp. 301-317). Springer.

Lederman, N. G., Abd-El-Khalick, F., Bell, R. L., \& Schwartz, R. S. (2002). Views of Nature of Science Questionnaire: Toward valid and meaningful assessment of learners' conceptions of nature of science. Journal of Research in Science Teaching, 39(6), 497-521. https://doi.org/410.1002/tea.10034

Lima, R. R. (2017). Desenvolvimento do Conhecimento de Professores sobre Natureza da Ciência: Contribuições da história da ciência. [Development of Teachers' Knowledge on Nature of Science: Contributions from history of science (Masters dissertation), Universidade Federal de Minas Gerais, Belo Horizonte. Retrieved from https:// repositorio.ufmg.br/bitstream/1843/BUOS-AWGLUA/1/dissertac_a_o___rachel_ rodrigues_lima.pdf

Marcus, G. E., \& Fischer, M. (1986). Antropology as Cultural Critique: An experimental moment in the human sciences. University of Chicago Press.

Martins, A. F. P. (2015). Natureza da Ciência no ensino de ciências: uma proposta baseada em "temas" e "questões" [Nature of Science in Science Education: a proposal based on "themes" and "questions"]. Caderno Brasileiro de Ensino de Física, 32(3), $703-$ 737. http://dx.doi.org/10.5007/2175-7941.2015v32n3p703

Matthews, M. R. (1998). In Defense of Modest Goals when Teaching about the Nature of Science. Journal of Research in Science Teaching, 35(2), 161-174, https://doi.org/110.1002/ (SICI)1098-2736(199802)199835:199802<199161::AID-TEA199806>199803.199800. CO;199802-Q 
Matthews, M. R. (2012). Changing the Focus: From nature of science to features of science. In M. S. Khine (Ed.), Advances in Nature of Science Research (pp. 3-26). Springer. McComas, W. F. (2008). Seeking Historical Examples to Illustrate Key Aspects of the Nature of Science. Science \& Education, 17(2-3), 249-263. https://doi.org/10.1007/ s11191-007-9081-y

Millar, R., \& Osborne, J. (1998). Beyond 2000: Science education for the future. King's College and London School of Education.

Moura, C., Camel, T., \& Guerra, A. (2020). A Natureza da Ciência pelas Lentes do Currículo: Normatividade curricular, contextualização e os centidos de ensinar sobre Ciências [Nature of Science through Curriculum Theory' Lenses: Curricular Normativity, Contextualization and the Meaning of Teaching About Science]. Ensaio Pesquisa em Educação em Ciências, 22, 1-27. https://doi.org/10.1590/1983-21172020210114

Neiva, L. (2020). Desde Galileu, negação da ciência passou do campo religioso para o político, diz astrofísico [Since Galileo, denial od science has shifted from the religious to the political area, says astrophysicist]. https:/www.uol.com.br/tilt/noticias/ bbc/2020/05/30/desde-galileu-negacao-da-ciencia-passou-do-campo-religioso-para-opolitico-diz-astrofisico.htm

Nielsen, K. (2013). Scientific Communication and the Nature of Science. Science \& Education, 22(9), 2067-2086. https://doi.org/10.1007/s11191-012-9475-3

Olson, J. (2018). The Inclusion of the Nature of Science in Nine Recent International Science Education Standards Documents. Science \& Education, 27(7-8), 637-660. https://doi.org/10.1007/s11191-018-9993-8

Osbeck, L. M., Nersessian, N. J., Malone, K. R., \& Newstetter, W. C. (2011). Science as Psychology: Sense-making and identity in science practice. Cambridge University Press.

Osborne, J., Collins, S., Ratcliffe, M., Millar, R., \& Duschl, R. (2003). What "Ideas-aboutScience" Should Be Taught in School Science? A Delphi Study of the Expert Community. Journal of Research in Science Teaching, 40(7), 692-720. https://doi.org/610.1002/ tea. 1010

Oxford Dictionary. (2016). Oxford Dictionary 2016 word of the year. https:// en.oxforddictionaries.com/word-of-the-year/word-ofthe-year-2016

Pickering, A. (1995). The Mangle of Practice: Time, agency, \& science. The University of Chicago Press.

Roberts, D. A. (2011). Competing Visions of Scientific Literacy: The influence of a science curriculum policy image. In C. Linder, L. Östman, D. A. Roberts, P.-O. Wickman, G. Erickson, \& A. Mackinnon (Eds.), Exploring the Landscape of Scientic Literacy (pp. 1127). Routledge. 
Rosenberg, A. (2005). Why Philosophy of Science? In A. Rosenberg (Ed.), The Philosophy of Science: A contemporary introduction (pp. 1-20). Routledge.

Santos, M.(2018). Uso da História da Ciência para Favorecer a Compreensão de Estudantes do Ensino Médio sobre Ciência [Use of History of Science to Support High School Students' Understanding about Science]. Revista Brasileira de Pesquisa em Educação em Ciências, 18(2), 641-668. https://doi.org/610.28976/21984-22686rbpec2018182641

Santos, M. (2019). Compreendendo Visões de Estudantes sobre Ciências e suas Relações com o Ensino Fundamentado em Modelagem em Contextos Cotidiano, Científico e Sociocientífico [Understanding Students' Views about Science and their Relations to Modelling-based Teaching in Routine, Scientific and Socio-scientific Contexts]. (Masters dissertation), Universidade Federal de Minas Gerais, Belo Horizonte. https:// repositorio.ufmg.br/bitstream/1843/BUOS-BBLJX2/1/disserta_o__monique_santos. pdf

Sasseron, L. H., \& Carvalho, A. M. P. (2011). Alfabetização Científica: Uma revisão bibliográfica [Scientific Literacy:A bibliographical review]. Investigações em Ensino de Ciências, 16(1), 59-77.

Schwartz, R. S., Lederman, N. G., \& Lederman, J. S. (2008). An Instrument to Assess Views of Scientific Inquiry: The VOSI questionnaire. Paper presented at the Annual Meeting of the National Association for Research in Science Teaching, Baltimore, MD.

Shadish, W. R., Fuller, S., \& Gorman, M. E. (1994). Social Psychology of Science: A conceptual and empirical eesearch program. In W. R. Shadish \& S. Fuller (Eds.), The Social Psychology of Science (pp. 3-122). Guilford Press.

Shadish, W. R., Houts, A. C., Gholson, B., \& Neimeyer, R. A. (1989). The Psychology of Science: An introduction. In B. Gholson, W. R. Shadish, R. A. Neimeyer, \& A. C. Houts (Eds.), Pshychology of Science: Contributions to metascience (pp. 1-16). Cambridge University Press.

Siqueira, E. C. P. (2019). A Inserção e Discussão de Aspectos de Natureza da Ciência em Sala de Aula a partir do Filme O Menino que Descobriu o Vento [The Introduction and Discussion of Aspects of Nature of Science in Science Classes from the Film The Boy Who Harnessed the Wind]. (Undergraduation Final Essay), Universidade Federal de Minas Gerais, Belo Horizonte.

van Dijk, E. M. (2011). Portraying Real Science in Science Communication. Science Education, 95(6), 1086-1100. https://doi.org/1010.1002/sce.20458

Vermeir, K. (2013). Scientific Research: Commodities or commons? Science \& Education, 22(10), 2485-2510. https://doi.org/10.1007/s11191-012-9524-y

Weinstein, M. (2008). Finding Science in the School Body: Reflections on transgressing the boundaries of science education and the social studies of science. Science Education, 92(3), 389-403. https://doi.org/310.1002/sce.20267 
Wong, S. L., \& Hodson, D. (2010). More from the Horse's Mouth: What scientists say about science as a social practice. International Journal of Science Education, 32(11), 1431-1463. https://doi.org/1410.1080/09500690903104465

Monique Santos

(1) https://orcid.org/0000-0001-6042-0312 Universidade Federal de Minas Gerais

Faculdade de Educação, Programa de Pós-graduação em Educação: Conhecimento e Inclusão Social Belo Horizonte, Minas Gerais, Brazil moniquersqui@gmail.com

Poliana Maia

[1] https://orcid.org/0000-0001-9778-4486 Universidade Federal de Viçosa Campus Florestal Instituto de Ciências Exatas e Tecnológicas Florestal, Minas Gerais, Brazil poliana.maia@ufv.br

Rosária Justi

[1] https://orcid.org/0000-0001-6535-5046 Universidade Federal de Minas Gerais Instituto de Ciências Exatas Departamento de Química Belo Horizonte, Minas Gerais, Brazil rjusti@ufmg.br

Submitted on 04th April 2020 Accepted on 25th June 2020 Published on 15th July 2020 